This item was submitted to Loughborough's Research Repository by the author.

Items in Figshare are protected by copyright, with all rights reserved, unless otherwise indicated.

\title{
Effect of thermally grown oxides on colour development of stainless steel
}

PLEASE CITE THE PUBLISHED VERSION

http://dx.doi.org/10.1179/0960340914Z.00000000083

\section{PUBLISHER}

(c) W. S. Maney \& Son Ltd

\section{VERSION}

AM (Accepted Manuscript)

\section{PUBLISHER STATEMENT}

This work is made available according to the conditions of the Creative Commons Attribution-NonCommercialNoDerivatives 4.0 International (CC BY-NC-ND 4.0) licence. Full details of this licence are available at: https://creativecommons.org/licenses/by-nc-nd/4.0/

\section{LICENCE}

CC BY-NC-ND 4.0

\section{REPOSITORY RECORD}

Higginson, Rebecca L., Charles P. Jackson, E.L. Murrell, P.A.Z. Exworthy, Roger J. Mortimer, David R. Worrall, and G.D. Wilcox. 2019. "Effect of Thermally Grown Oxides on Colour Development of Stainless Steel". figshare. https://hdl.handle.net/2134/17150. 


\title{
The Effect of Thermally Grown Oxides on the Colour Development of Stainless Steel
}

\author{
R.L.Higginson ${ }^{1}$, C.Jackson ${ }^{1}$, E.Murrell ${ }^{1}$, A.Exworthy ${ }^{1}$, R.J.Mortimer ${ }^{2}$, D.R.Worrall ${ }^{2}$ \\ G.D.Wilcox ${ }^{1}$
}

1. Department of Materials, Loughborough University, Loughborough, LE1 1 3TU, UK

2. Department of Chemistry, Loughborough University, Loughborough, LE11 3TU, UK

\begin{abstract}
Stainless steels are used in an array of applications where their ability to take on colour is of aesthetic value. Although thermal colouring (heat tinting) is known, particularly in terms of its effect on welds, the surface development of thermally coloured stainless steel has not been considered in detail. This paper demonstrates the colour development of a bright annealed 304 stainless steel with time at temperature. The colour development has been quantified using colour spectrophotoscopy and the colour related to the growth of surface oxide features by Scanning Electron Microscopy and the chemical profiles by X-ray Photoelectron Spectroscopy (XPS). There is a clear development of both the oxide thickness and chemistry, with increasing time with small nodules being the main features seen across the surface of the samples with time. The oxides have been shown to comprise of an outer iron rich oxide and an inner chromium/iron spinel layer.
\end{abstract}

Keywords: Stainless Steel, Thermal Colouring, Heat Tint, Oxidation

\section{Introduction}

Stainless steels are used extensively for a wide range of applications, including those for architectural buildings and structures. They are utilised for a variety of architectural features including external cladding and internal designs such as facings on walls in communal areas due to their good corrosion resistance and aesthetic appeal. Stainless steel can be bulk processed to produce a range of surface finishes including near mirror finish, by bright annealing, through to highly textured surfaces. To enhance their aesthetics, a range of colours can be produced on stainless steel which not only gives the architect a vast range of material looks but can also potentially assist in the protection of the metal from the environment.

Colours can be applied using a number of different procedures from chemical methods to physical vapour deposition (PVD). Chemical colouring involves immersing the stainless steel 
in hot chromic and sulphuric acid solution causing a uniform oxide film displaying interference colour to be formed on the surface ${ }^{1,2}$. The film thickness increases with immersion time ${ }^{1}$, and varying the film thickness causes a change in the colour of the film. Stainless steel has also been successfully coloured using electrochemical methods involving electrolytic solutions containing $\mathrm{Cr}^{6+}$ ions ${ }^{3,4}$ and also in solutions containing no $\mathrm{Cr}^{6+}$ ions ${ }^{5-7}$. PVD involves vaporising the coating material before being deposited as a thin film of component. A range of coating materials can deposited depending on the colour required and the application of the final component.

Colours can also be generated by 'temper' colouring where thermal oxides are developed on the surface of the metal through heat treatments ${ }^{8,9}$. Temper colours are usually produced at a set heat treatment temperature over a range from $300-850^{\circ} \mathrm{C}$, although the colour developed is also dependent on the time at temperature and therefore the oxide character and thickness as the colours are produced by an interference affect from the thin oxide film. At higher temperatures the colours are generally reported as grey or dark grey as thicker oxides are developed ${ }^{8,9}$.

Although colouring via thermal oxide growth is relatively well known, the physical nature of the oxidised surface has not been fully investigated. This paper considers the controlled growth of thermal oxides, with the colour correlated to the oxide structures and morphologies. The oxides have been characterised using advanced analytical techniques including X-ray Photoelectron Spectroscopy (XPS) and Scanning Electron Microscopy (SEM).

\section{Experimental Procedure}

Austenitic grade stainless steel Type 304 (1.4301) was supplied as 2mm sheet in the bright annealed condition. The material was cut into $20 \mathrm{~mm}^{2}$ coupons and cleaned in acetone before being oxidised in a box furnace, in laboratory air, at $650^{\circ} \mathrm{C}$ for increasing amounts of time from 1-10 minutes. Following oxidation the colour of the coupons was measured using an Xrite colour spectrophotometer using both $\mathrm{L}^{*} \mathrm{a}^{*} \mathrm{~b}^{*}$ and $\mathrm{L}, \mathrm{c}, \mathrm{h}$ measurements. In both systems $\mathrm{L}^{*} / \mathrm{L}$ gives a measure of the "lightness". In $\mathrm{L}^{*} \mathrm{a}^{*} \mathrm{~b}^{*}, \mathrm{a}^{*} \mathrm{~b}^{*}$ represent the colour component (ared to green and b-yellow to blue) and in L,c,h, c gives a measure of chroma or saturation and h the hue ${ }^{10}$. 
The oxides were imaged using optical microscopy with colour micrographs taken to study the colour profile across the samples. The surfaces of the samples were examined using Scanning Electron Microscopy (SEM) in a LEO 1530 VP Field Emission Gun SEM (FEGSEM). Chemical depth profiling was carried out using a Thermoscientific K-Alpha Xray Photoelectron Spectroscopy (XPS) using a monochromated Ka Al X-ray source. The etch depth was approximated against a $\mathrm{Ta}_{2} \mathrm{O}_{5}$ standard.

\section{Results and Discussion}

Fig. 1 shows the colour development with time for the samples up to 10 minutes plotted in $\mathrm{L}^{*} \mathrm{a}^{*} \mathrm{~b}^{*}$ and $\mathrm{L}, \mathrm{c}, \mathrm{h}$ values ( 0 indicates the as received metal surface). The initial sample has a low saturation (c) value as would be expected for a silver grey metal, Fig.1b. As the time at temperature increases the colours change through yellow to red to blue. There is a general decrease in the $\mathrm{L}$ values as the time increases, this is expected as the oxide which develops on the surfaces thickens over this time. The $\mathrm{L}$ value reaches a plateau after 5 minutes. The $\mathrm{a}^{*} \mathrm{~b}^{*}$ values clearly show the change in colour from the yellow (high $b^{*}$ ) through to red (high $\mathrm{a}^{*}$ ) then moving to blue as $b^{*}$ becomes negative. The $h$ value (Fig. $1 b$ ) shows that there is a clear change at $\sim 6$ minutes where the value goes from 0 to $\sim 350$, or from yellow to pink. The colour saturation (c value) remains low but reaches a peak at 3 minutes which corresponds to the gold-yellow colour developed at this time.
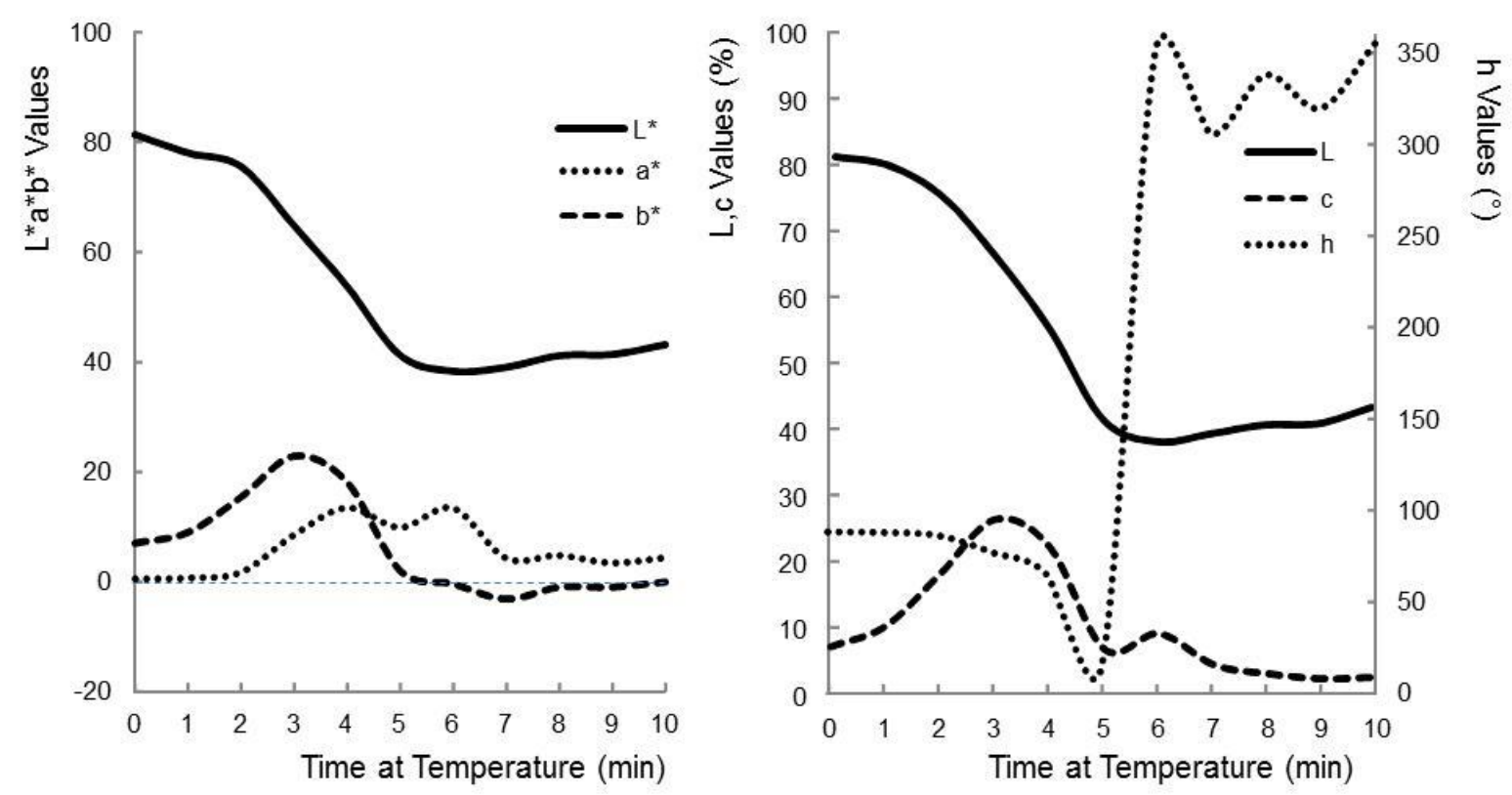

Figure 1: Colour development with time at temperature measured in (a) L*a*b* and (b) L,c,h values 
Optical micrographs of the samples are shown in Fig. 2. As the material is bright annealed the grain structure is clearly visible under the microscope, needing no metallographic preparation. There is some alignment of the features along the rolling direction of the original sheet. As the oxidation time increases, the colour change can be seen in the optical microscopy although the exact colours are dependent on the illumination used but it does, however, give a good representation of how the colour changes with oxidation time. The most evident changes are from 3 to 7 minutes as the material goes through gold to red to blue.

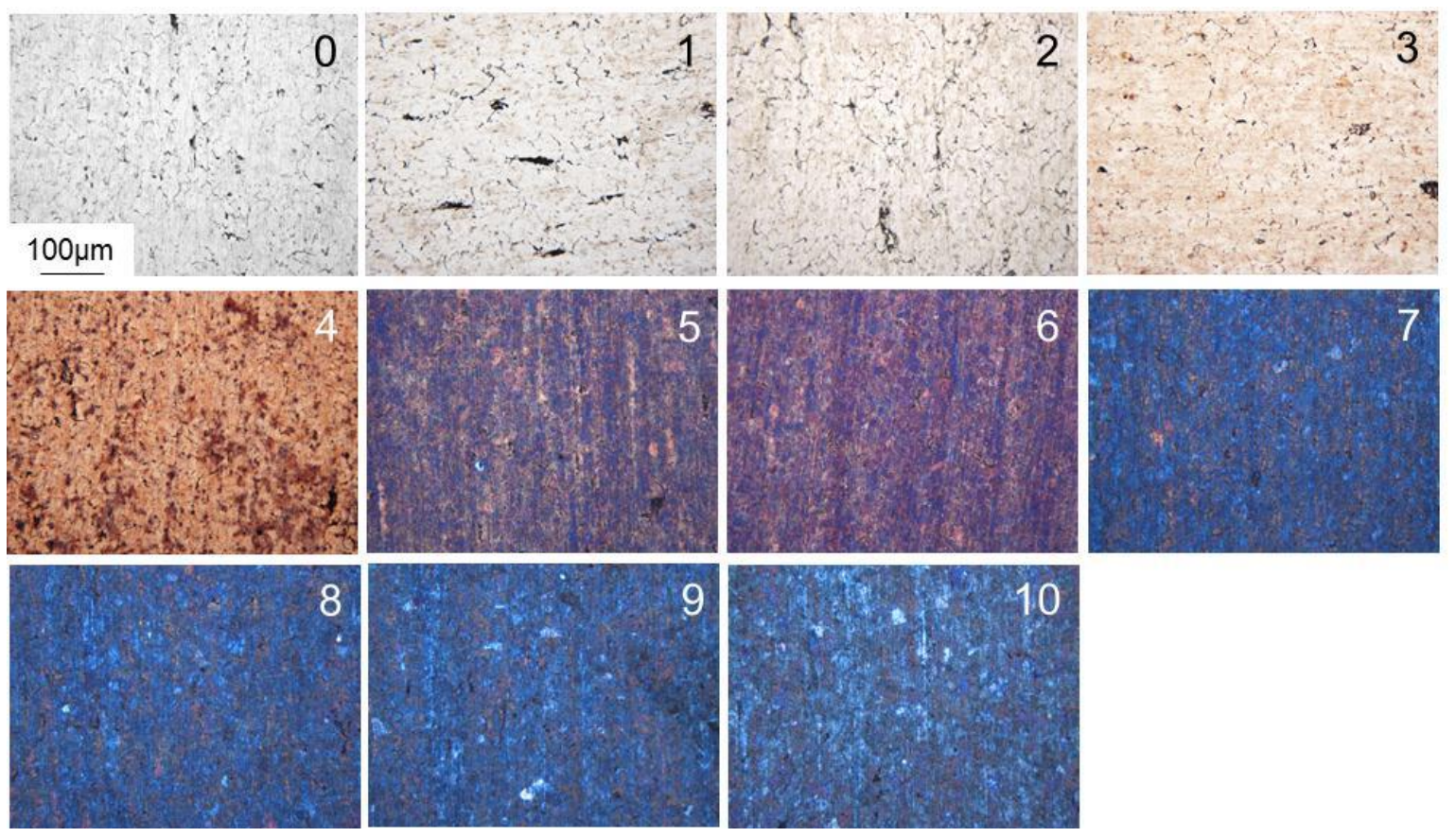

Figure 2: Optical micrographs of the samples oxidised for $0-10$ minutes at $650^{\circ} \mathrm{C}$ in laboratory air.

Fig.3 (a) shows SEM micrographs of the surface of the as received material. The grains and grain boundaries are clearly visible even without any metallographic preparation. The bright annealing process has thermally etched the surface of the materials with ridges on the surface which appear to be related to the orientation of the grains. An XPS depth profile of the as received material is shown in Fig. 4(a). As would be expected for a stainless steel there is a very thin oxide layer on the surface of the metal. The chemical profiles show an iron rich outer oxide layer and a chromium/iron rich inner oxide layer, this is consistent with the XPS observations on 304 who also observed a similar profile on a $1 \mu \mathrm{m}$ polished surface ${ }^{11}$. Analysis of the XPS data against a $\mathrm{Ta}_{2} \mathrm{O}_{5}$ standard showed this layer to be $\sim 10 \mathrm{~nm}$ in 
thickness. Ziemniak et al. ${ }^{12}$ observed a native oxide layer of $1-2 \mathrm{~nm}$ on an electropolished surface and a machined sample. The layer observed in the present study is slightly thicker which could be due to a thicker oxide being developed during the bright annealing process.
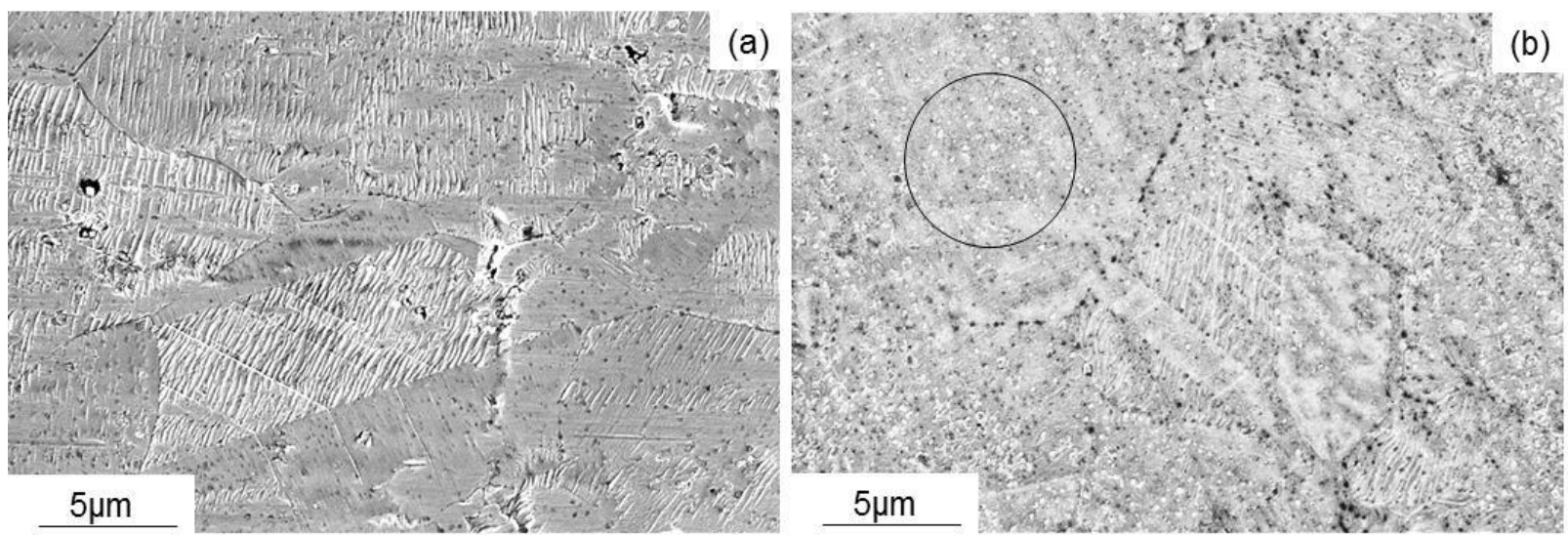

Figure 3: SEM micrographs of (a) the as-received (bright annealed) surface and (b) following oxidation for 3 minutes, the circle indicates an area where nodules have started to form

After 3 minutes (Fig. 3(b)) the ridges are still visible across the grains. The grain boundaries are visible as lines of tiny dark spots. Across the surface of the grains small oxide nodules have started to form in some of the grains, these are visible as the light spots as indicated by the circle in Fig. 3(b). As the time increases the size and propensity of these oxide nodules increased. Fig. 5 shows the surface after treatment for 7 minutes. At this time the individual grains are still visible on the surface although more obscured by the formation of the oxide nodules. These nodules are not however, homogeneous across the surface of the sample. Fig. 5(b) shows a higher magnification SEM micrograph of the region indicated in Fig. 5(a). This region has patches where the oxide nodules have yet to form surrounded by areas where nodule formation are at varying stages of development. The inhomogeneous formation of the oxide structure across the surface of the samples causes the slight changes in colour across the surface of the samples as seen in the optical micrographs in Fig.2. The 7 minute samples, although generally blue in colour, show patches of pink and gold still remaining, although the sample when examined by eye appears blue to the observer.

Fig. 4(b) shows the full XPS depth scan for the samples treated for 8 minutes. At this time the oxide is clearly thicker. At the surface the oxide is primarily iron oxide with little or no chromium oxide detected. After about 200s the chromium oxide line increases indicating that at this point there is an iron-chromium spinel oxide layer. The chromium and iron oxide 
percentages then decrease as the iron and chromium metal percentages increase although at 2000s the metal compositions have not reached that of the substrate metal. The tail in the data may be due to the re-passivation of the metal as new metal is revealed during the etching, as the analysis was not carried out under an ultra-high vacuum although the iron oxide line has decreased to an almost zero level.
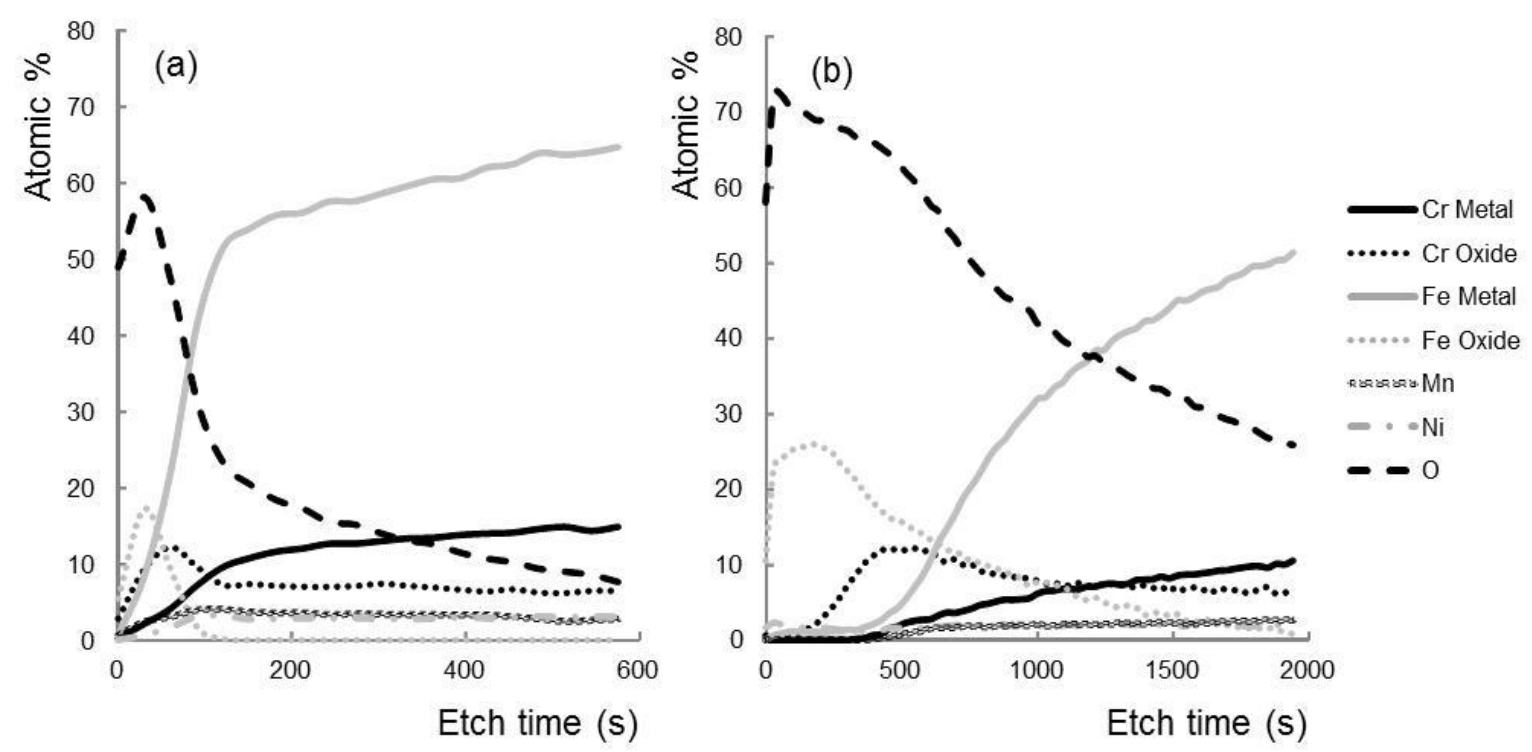

Figure 4: XPS depth profiles of (a) and as received material and (b) after oxidation at $650^{\circ} \mathrm{C}$ for 8 minutes
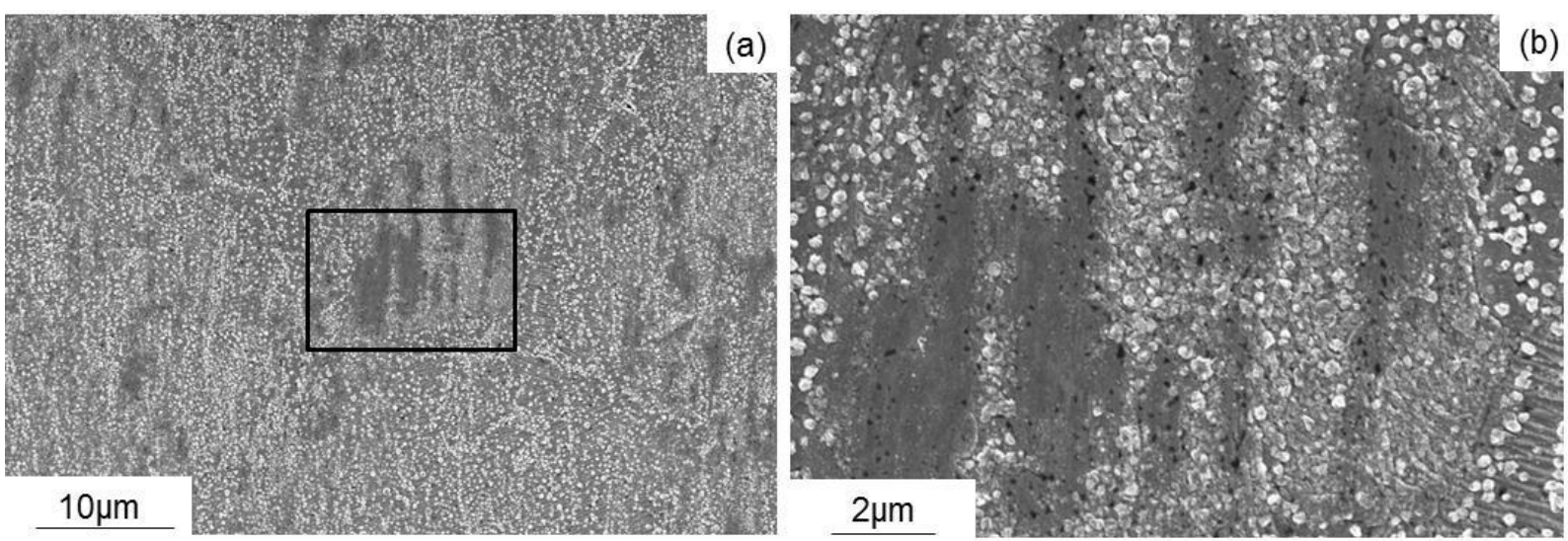

Figure 5: (a) SEM micrographs of the sample surface following oxidation for 7 minutes (b) showing a higher magnification of the region highlighted in (a)

Fig. 6 shows SEM micrographs of the surface of the sample after 10 minutes at $650^{\circ} \mathrm{C}$. There is a more homogeneous cover of the small oxide nodules over the surface of the sample, Fig. 6 (a) although there are very small patches where the fraction is lower. Fig.6 (b) shows a higher magnification of the oxide nodules. The nodules are less than 500nm in size and have 
a random globular shape with no obvious crystallographic features. Nodules have previously been reported to form on 304 stainless steel during high temperature oxidation ${ }^{12,13}$. These nodules were however formed at higher temperatures and for considerably longer oxidation times and as such are generally larger and exhibit crystallographic structure such as octahedral shapes, platelets or whiskers ${ }^{13,14}$.
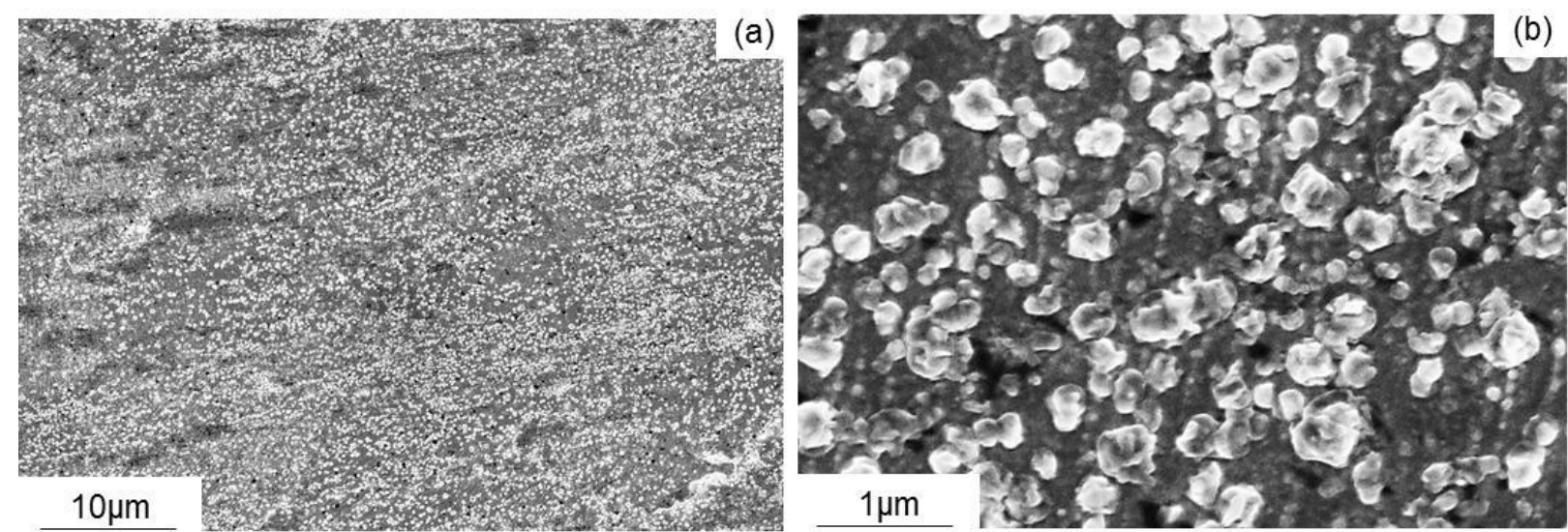

Figure 6: SEM micrographs of the sample surface following oxidation for 10 minutes

XPS depth profiles for iron oxide, chromium oxide and oxygen species with oxidation time are shown in Fig. 7. The iron oxide profiles (Fig. 7(a)) show that the initial native iron oxide peak seen in the as received metal thickens as the time increases up to 3 minutes. Between 3 and 7 minutes the profiles are very similar with an initial peak followed by a plateau as the etch time increases. For the 8-10 minute samples after the initial peak the iron oxide content decreases rapidly. The chromium oxide plots in Fig.7(b) show sharp peaks for the as received and the 1-3 minute samples being further into the surface than the iron oxide peak at all times. The profiles of the 4-10 minutes samples are all very similar, after the initial peak the curves plateau to $\sim 7$ atomic percent. Fig. 7 (c) show the oxygen profiles with time. As expected, as the time at temperatures increases, the thickness of the oxides increases. The 710 minutes samples show a very similar oxide profile.

The oxides developed consist of two layers, the outer layer is predominately iron oxide and the inner layer an iron-chromium oxide. Saeki et al. ${ }^{11}$ showed a similar result on 304 oxidised at $1000^{\circ} \mathrm{C}$ for short times. By X-ray diffraction they concluded that the outer layer is $\mathrm{M}_{2} \mathrm{O}_{3}$ where $\mathrm{M}$ is $\mathrm{Fe}$ or $\mathrm{Cr}$. In the present study as the outer layer is iron oxide rich it can be concluded that the nodules are primarily $\mathrm{Fe}_{2} \mathrm{O}_{3}$ or hematite. Saeki et al. showed the inner 
layer to be the spinel type oxide $\mathrm{AB}_{2} \mathrm{O}_{4}$, where in their case $\mathrm{AB}$ was $\mathrm{Mn}, \mathrm{Fe}$ or $\mathrm{Cr}$. In the present study the inner layer is predominantly iron and chromium with little or no manganese present.
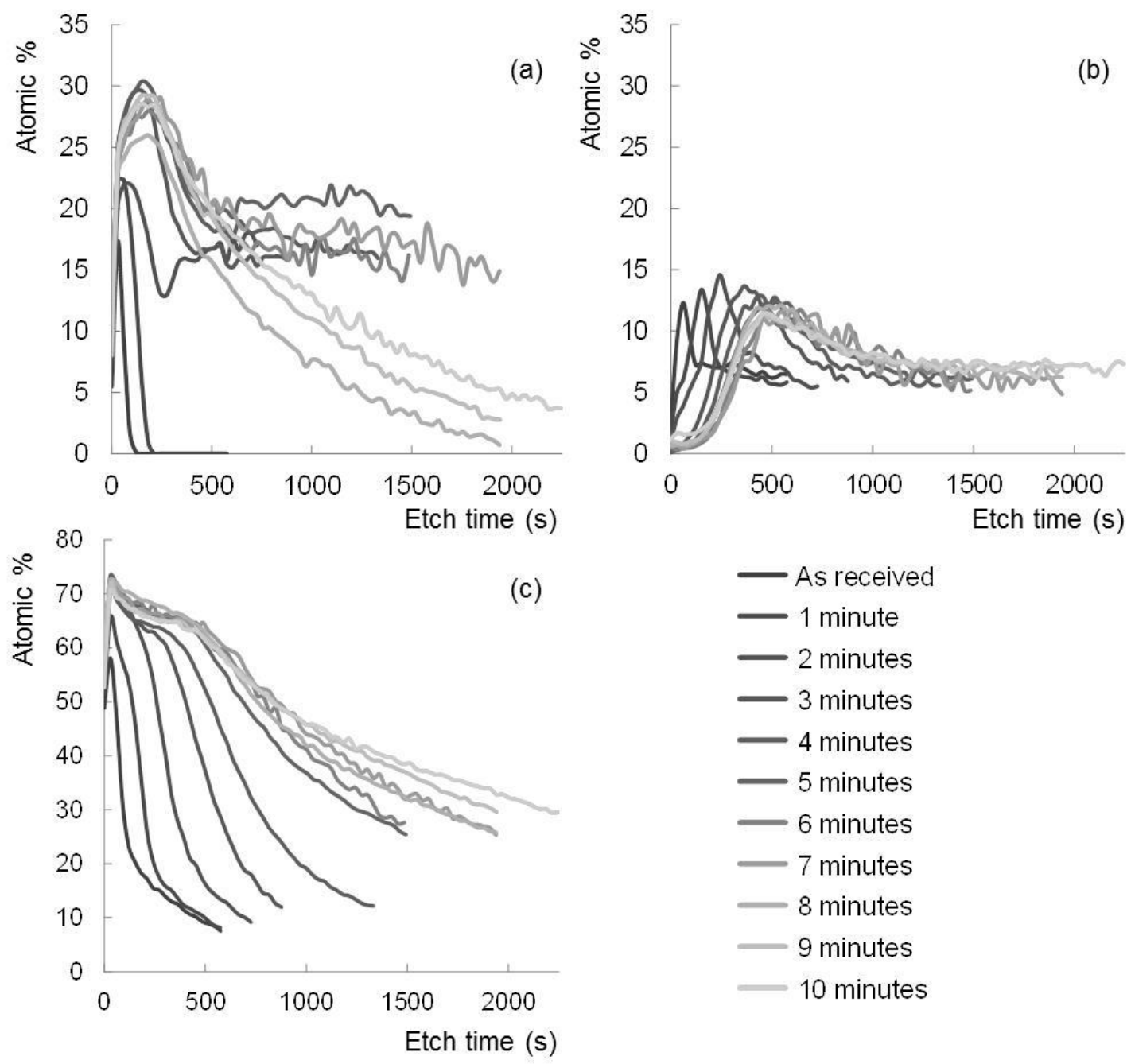

Figure 7: XPS depth profiles for (a) the iron oxide, (b) chromium oxide and (c) oxygen with time at $650^{\circ} \mathrm{C}$

The colour development of the samples can be related to the oxide thickness and nodule features. As the time increases the thickness of the oxide increases as the colours go through yellow to red to blue, Figs 1 and 2. Once the blue colour has developed after 7 minutes, there is less change in the oxide thickness as shown by the XPS results, Fig.7. After 7 minutes the only change in the oxide surface is the nucleation of more nodules across the surface of the samples such that after 10 minutes they are more homogenously distributed over the surface, Fig.6. 


\section{Conclusions}

Thermal oxide colours can be developed at a single oxidation temperature by increasing the exposure time, up to 10 minutes at $650^{\circ} \mathrm{C}$. These oxides consist of an outer iron oxide, hematite $\mathrm{Fe}_{2} \mathrm{O}_{3}$, and an inner iron-chromium spinel. The outer layer is characterised by small (less than 500nm) nodules which become increasing homogeneous as the time increases. After $\sim 7$ minutes the colour remains blue and there is no change in the oxide thickness detected up to 10 minutes. The only change over this time is the continued nucleation of the oxide nodules.

\section{References}

1. Evans, T. E., Hart, A. C., James, H. \& Smith, V. A., A New Process for Colouring Stainless Steel. Trans. Inst. Met. Finish. 50, 77-79 (1972)

2. Evans, T. E., Hart, A. C. \& Skedgell, A. N., The Nature of the Film on Coloured Stainless Steel. Trans. Inst. Met. Finish. 108-112 (1973)

3. Lin, C. J. \& Duh, J. G., The predominant operation parameters and alternative controllability in the square-wave current pulse process for colouring SUS 304 stainless steel. Surf. Coatings Technol. 70, 79-85 (1994)

4. Ogura, K., Lou, W. \& Nakayama, M., Coloration of Stainless Steel at Room Temperature by Triangular Current Scan Method. Electrochim. Acta 41, 2849-2853 (1996)

5. Vasconcelos, K. D. O., Bocchi, N., Rocha-Filho, R. C. \& Biaggio, S. R., An Environmentally Friendly and Practical Method for Obtaining Color on Stainless Steel by Interference. J. Electrochem. Soc. 152, B491 (2005)

6. Fujimoto, S., Shibata, T., Wada, K. \& Tsutae, T., The electrochemical conditions for coloured film formation on Type 304 stainless steel with square wave polarization. Corros. Sci. 35, 147-152 (1993)

7. Zhang, J., Yan, L., Qiao, Y., Cao, C. \& Zhou, G.-D., A “green” process for colouring stainless steel. Trans. Inst. Met. Finish. 83, 95-98 (2005)

8. Esih, I., Altar, V. \& Juraga, I., Influence of thermal oxides on pitting corrosion of stainless steel in chloride solution. Corros. Sci. Tech. 40, 110-120 (2005)

9. Gulbransen, E.A., \& Andrew, K.F., Oxidation Studies on 304 stainless steel.

J.Electrochem.Soc. 109 (7), 560-564 (1962)

10. Berns, R.S. Billmeyer and Saltzmans's Principles of Color Technology, John Wiley \& Sons, Inc. New York (2000) 
11. Isao, S., Takahiro, S., Ryusaburo, F., Hindetaka, K., Tsuneo, N., Katsumi, M., \& Masahiko, I., Growth process of protective oxides formed on Type 304 and 430 stainless steels at 1273K, Corros. Sci. 40 (8) 1295-1302 (1998)

12. Ziemniak, S.E., Hanson, M., \& Sander, P.C., Electropolishing effects on corrosion behavior of 304 stainless steel in high temperature, hydrogenated water, Corros. Sci. 50, 2465-2477 (2008)

13. Huntz, A.M., Reckmann, A., Haut, C., Sévérac, C., Herbst, M., Resende. F.C.T., \&

Sabioni A.C.S., Oxidation o AISI 304 and AISI 439 stainless steel, Mat.Sci.Eng.A, 447, 266$276(2007)$

14. Higginson, R.L., \& Green, G., Whisker Growth Morphology of High Temperature Oxides Grown on 304 Stainless, Corros. Sci. 53 (5) 1690-1693 (2011) 
